\title{
Peningkatan Akurasi Sensor GY-521 MPU- 6050 dengan Metode Koreksi Faktor Drift
}

\author{
Fakhruddin Mangkusasmito $^{1}$, Dista Yoel Tadeus ${ }^{1}$, Heru Winarno ${ }^{2}$, Eko Ariyanto ${ }^{2}$ \\ ${ }^{1}$ STr.Teknologi Rekayasa Otomasi, Sekolah Vokasi Undip, Semarang, Indonesia \\ ${ }^{2}$ STr. Teknik Listrik Industri, Sekolah Vokasi Undip, Semarang, Indonesia \\ fakhm17@lecturer.undip.ac.id
}

Diterima 14 Oktober 2020

Disetujui 11 November 2020

\begin{abstract}
GY-521 MPU-6050 Module is a core module MPU-6050, which is a 6 axis Motion Processing Unit. This sensor can be categorized as an Inertial Measurement Unit (IMU) sensor, which utilizes measurement systems such as gyroscopes and accelerometers to estimate the relative position, velocity, and acceleration of an object. A common accuracy problem in using IMU sensors, including the GY-521 MPU-6050, is the drifting phenomenon. This phenomenon results in a deviation between the actual conditions (position, angular velocity) and the sensor readings. Drift is caused by the accumulation of errors that arise from calculating the integral of the acceleration. This study proposes a drift error correction method at the sensor output using the calibration of the calculation of the average offset error sensor and the sensor fusion method between the information obtained from the gyroscope and accelerometer in the module, the tests were carried out using the Arduino Uno microcontroller. From the test results, it is found that the combination of the initial system calibration implementation and the use of the fusion sensor concept can provide better performance with the MSE analysis results for the roll position of 0.00290 and the pitch position of 0.00470 and the drifting error rate at the yaw angle position of 000820 / second or down $62.72 \%$.
\end{abstract}

Index Terms - IMU, MPU-6050, drifting, calibration, sensor fusion, Arduino

\section{PENDAHULUAN}

Inertial Measurement Unit (IMU) merupakan alat yang memanfaatkan sistem pengukuran seperti gyroskop dan akselerometer untuk memperkirakan posisi relatif, kecepatan, dan akselerasi dari suatu benda. Secara umum IMU digunakan untuk keperluan sistem navigasi [1]. Untuk keperluan sistem navigasi diperlukan informasi kecepatan sudut dan posisi sudut [2], dan seringkali digunakan sensor tambahan seperti magnetometer dan sensor temperatur[3]. Sensor IMU dapat pula diintegrasikan dengan sistem odometri untuk menghasilkan informasi posisi dan referensi untuk sistem autonomus di robot pertambangan seperti yang diperlihatkan oleh Gambar 1 berikut[4].

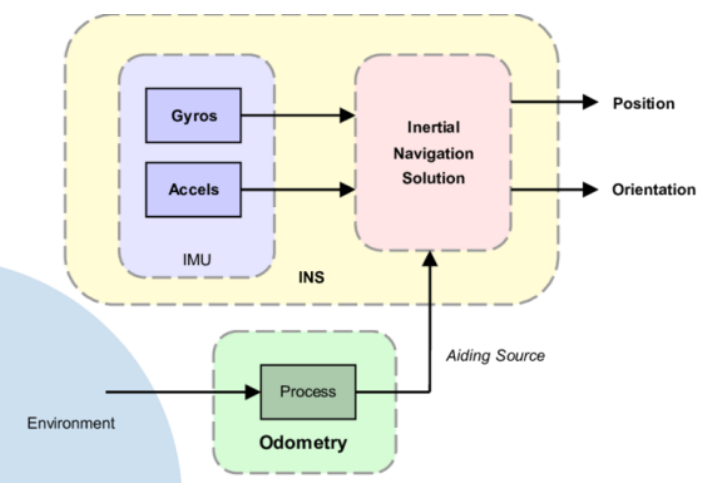

Gambar 1. Integrasi IMU-Odometri untuk menghasilkan informasi navigasi

Sensor jenis microelectromechanical systems (MEMS), merupakan jenis sensor yang dibangun berdasarkan teknologi mikrosistem yang didefinisikan sebagai elemen mekanik dan elektromekanik dalam bentuk mikro dibuat dengan dengan teknik pabrikasi mikro. Selain sifatnya yang compact dan berdimensi relative rendah, tipe sensor MEMS memilikki konsumsi daya yang rendah, sehingga cocok digunakan untuk keperluan sistem navigasi [5]. GY-521 MPU6050 Module adalah sebuah modul berinti MPU-6050 yang merupakan 6 axis Motion Processing Unit dengan penambahan regulator tegangan dan beberapa komponen pelengkap lainnya yang membuat modul ini siap dipakai dengan tegangan supply sebesar 3-5VDC. Sensor MPU-6050 berisi sebuah MEMS Accelerometer dan sebuah MEMS Gyro yang saling terintegrasi.(https://invensense.tdk.com/products/moti on-tracking/6-axis/mpu-6050/). Selain dimensi yang tepat diperlukan pula performa dan akurasi yang baik dari sensor IMU agar dapat menghasilkan performa navigasi yang optimal untuk berbagai keperluan navigasi [6][7][8][9]. Sensor GY-521 MPU-6050 banyak digunakan untuk berbagai aplikasi karena mudah digunakan, dapat menghasilkan performa yang baik dan memilikki harga yang murah [10].

Permasalahan akurasi yang umum dalam penggunaan sensor IMU termasuk GY-521 MPU-6050 adalah fenomena drifting. Fenomena ini mengakibatkan adanya deviasi antara kondisi aktual (posisi, kecepatan sudut) dan hasil pembacaan sensor. 
Drift disebabkan oleh akumulasi kesalahan yang muncul dari perhitungan integral dari akselerasi[11]. Bias error yang terkecil yang pernah dilaporkan akibat perubahan temperatur untuk sensor ini ialah sebesar $62.71^{\circ} /$ jam untuk penggunaan pada range temperatur $40^{\circ} \mathrm{C}-85^{\circ} \mathrm{C}[12]$. Untuk mengetahui bentuk error tersebut seringkali desainer dapat membuat model matermatisnya[13]. Dan untuk mengkompensasi maupun menkoreksi kesalahan dapat digunakan beberapa filter seperti filter Kalman [14], atau filter dengan algortima cerdas berbasis fuzzy [15], atau dengan mengkombinasikan sensor IMU dengan sensor lain seperti GPS dalam skema sensor fusion [16]. Implementasi filter tersebut dapat memperbaikki performa sensor namun terdapat kompleksitas dalam implementasinya dalam bentuk program dan tambahan beban komputasi, khususnya bila diimplementasikan dengan menggunakan mikrokontroller biasa [17]. Penelitian ini mengajukan metode koreksi kesalahan drift pada output sensor GY-521 MPU-6050 yang mudah dalam implementasi serta memilikki beban komputasi yang ringan menggunakan kalibrasi hasil perhitungan rata-rata offset error sensor dan metode sensor fusion antara informasi yang diperoleh dari gyroscope dan accelerometer di dalam modul. Output sensor yang akan diperbaikki performanya ialah posisi sudut pada aksis x, y serta $z$. Pengujian ini dibangun dalam sebuah sistem yang berbasis mikrokontroller Arduino uno.

\section{METODOLOGI}

\section{A. Sistem Pengukuran Sudut}

Sistem pengukuran sudut pada penelitian ini terdiri dari sebuah sensor GY-521 MPU-6050, Arduino Uno untuk sistem akuisisi data, komputasi dan komunikasi data, serta sebuah PC untuk menampilkan data dalam bentuk grafik. Diagram dari sistem tersebut dapat dilihat pada Gambar 1. berikut

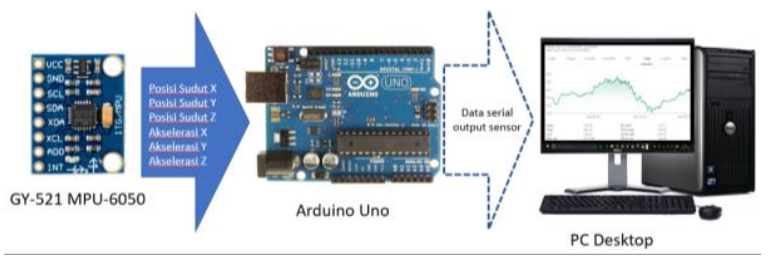

Gambar 1. Diagram Sistem

Sesuai Gambar 1. data mentah yang dihasilkan oleh sensor akan diolah oleh Arduino Uno, untuk kemudian dikirim ke PC melalui koneksi serial, dan hasilnya akan ditampilkan dalam bentuk grafik serta tabel dalam Ms. Excel. Spesifikasi sensor GY-521 MPU-6050 secara umum ialah sebagai berikut[18]:

- Tegangan kerja 2,375 V-3,46 V

- Terdiri dari 3 sumbu MEMS Gyroscope dan MEMS Accelerometer dengan masing-masing spesifikasi : $\checkmark$ MEMS Gyroscope :
○ Output digital dengan bentang skala \pm 250 , $\pm 500, \pm 1000$, dan $\pm 2000 \%$ detik

- 16 bit ADC

○ Arus operasi 3,6 mA

○ Arus standby $5 \mu \mathrm{A}$

$\checkmark$ MEMS Accelerometer

- Output digital dengan bentang skala $\pm 2 \mathrm{~g}$, $\pm 4 \mathrm{~g}, \pm 8 \mathrm{~g}$ dan $\pm 16 \mathrm{~g}$.

- 16 bit ADC

○ Arus operasi $500 \mu \mathrm{A}$

Sedangkan koneksi wiring antara sensor MPU 6050 dan Arduino Uno diperlihatkan oleh Gambar 2 beikut

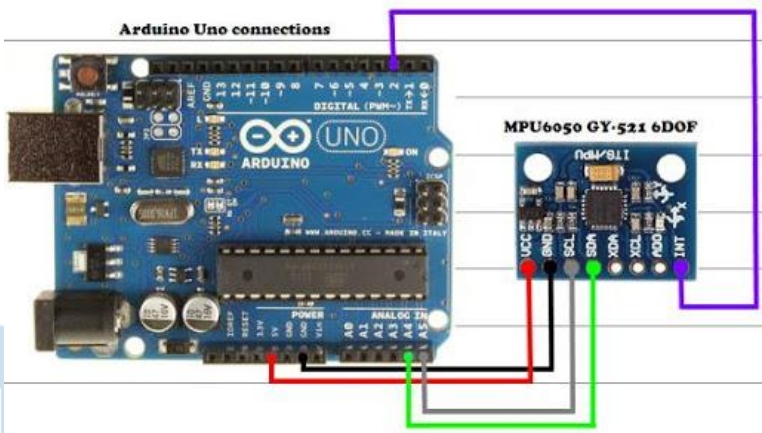

Gambar 2. Diagram wiring antara Arduino Uno dan MPU 6050

\section{B. Pengambilan Data Sensor}

Pada pengujian ini digunakan nilai full scale range (FSR) untuk masing-masing acceleremoter dan gyroscope sesuai default sistem yaitu +-2g dan 250 derajat/sekon. Adapun desainer dapat memilih nilai FSR yang diinginkan dengan menggunakan konfigurasi register sesuai dengan datasheet seperti yang ditunjukkan oleh Gambar 3. berikut

\begin{tabular}{|c|c|c|}
\hline AFS_SEL & Full Scale Range & LSB Sensitivity \\
\hline 0 & $\pm 2 g$ & $16384 \mathrm{LSB} / g$ \\
\hline 1 & $\pm 4 g$ & $8192 \mathrm{LSB} / g$ \\
\hline 2 & $\pm 8 g$ & $4096 \mathrm{LSB} / g$ \\
\hline 3 & $\pm 16 g$ & $2048 \mathrm{LSB} / g$ \\
\hline
\end{tabular}

Gambar 3. Konfigurasi register untuk FSR sensor

Pengujian dilakukan dengan menempatkan sistem sensor pada platform datar yang diasumsikan sebagai posisi sudut $0^{\circ}$ untuk masing-masing aksis $\mathrm{x}$, y dan $\mathrm{z}$. Data akan diambil selama 300 detik dengan periode sampling 0,5 detik untuk melihat fenomena drifting yang terjadi serta efek metode eliminasi yang diimplemantasikan.
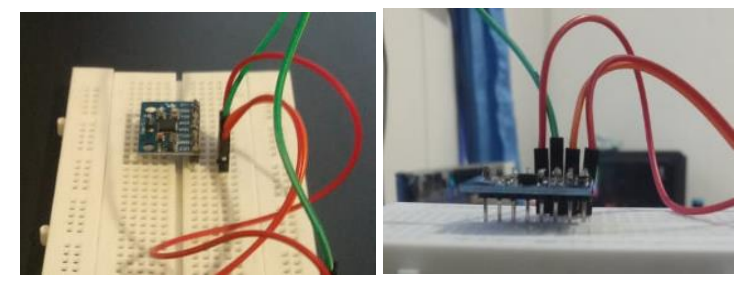

Gambar 3. Penempatan sistem sensor untuk pengujian 
Orientasi aksis dari modul sensor MPU-6050 diperlihatkan pada Gambar 4. berikut

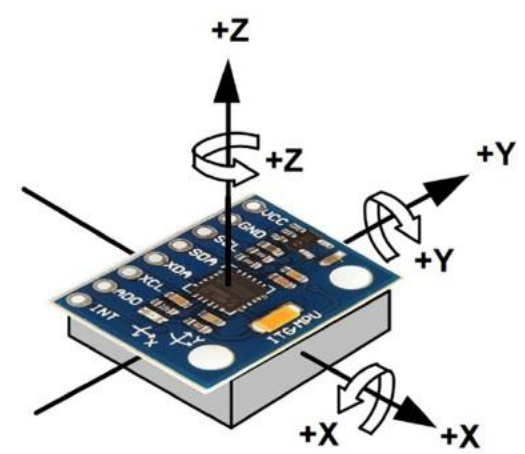

Gambar 4. Orientasi aksis pada sensor MPU-6050

Selanjutnya akan dilakukan beberapa skenario pengujian untuk melihat performa sistem yang dijelaskan sebagai berikut:

1. Akuisisi data posisi sudut dari hasil pembacaan gyroscope secara langsung.

2. Akuisisi data posisi sudut dengan menggunakan konsep sensor fusion antara pembacaan gyroscope dan pembacaan accelerometer.

3. Akuisisi data posisi sudut dengan menggunakan kalibrasi awal sistem pembacaan gyroscope.

4. Akuisisi data posisi sudut dengan menggunakan kalibrasi awal sistem dan konsep sensor fusion.

\section{ANALISIS DAN PEMBAHASAN}

Sesuai skenario pengujian yang dijelaskan pada bab sebelumnya maka didapat hasil pengujian sebagai berikut

\section{A. Akuisisi Data Posisi Sudut dari Hasil Pembacaan} Gyroscope Secara Langsung

Dari hasil pengujian yang telah dilakukan didapat grafik sebagai berikut

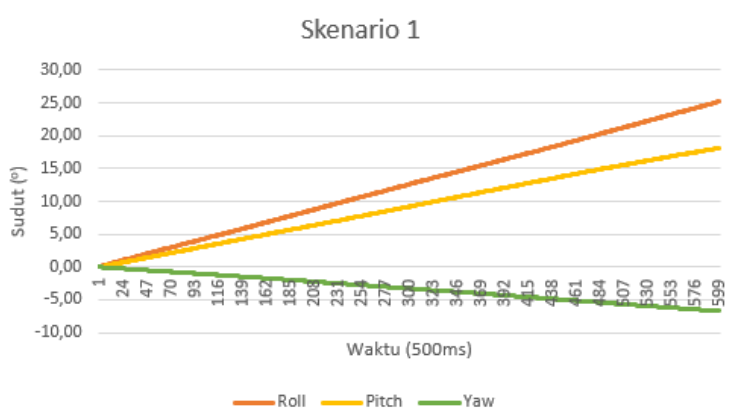

Gambar 5. Hasil pengujian Skenario 1

Gambar 5. memperlihatkan bahwa fenomena drifting terjadi untuk pembacaan ketiga posisi sudut, baik untuk sudut roll, pitch, dan yaw. Dari hasil pengujian dapat diketahui dengan nilai pembacaan awal roll $=0,05^{\circ}$, pitch $=-0,01^{\circ}$, dan yaw $=0,00^{\circ}$, dan nilai akhir pembacaan roll $=25,19^{\circ}$, pitch $=18,10^{\circ}$, dan yaw $=$ $6,73^{\circ}$ maka dapat diketahui dalam kurun waktu 300 detik laju kesalahan drifting untuk roll ialah sebesar $0,084 \%$ detik, sedangkan untuk pitch ialah sebesar $0,06 \%$ detik, dan yaw sebesar $0,022^{\circ}$ detik.

\section{B. Akuisisi Data Posisi Sudut Dengan Menggunakan Konsep Sensor Fusion Antara Pembaccan Gyroscope dan Pembacaan Accelerometer.}

Pada sekenario 2 ini hanya dilakukan pengambilan data pada sudut roll dan pitch, karena kita tidak dapat mengambil informasi sudut yaw dari accelerometer[19]. Pada skenario kedua ini akan dilakukan beberapa pengujian dengan melakukan tingkat kepercayaan sensor, yaitu

- $\quad$ gyroscope $75 \%$ - accelerometer $25 \%$

- $\quad$ gyroscope $80 \%$ - accelerometer $20 \%$

- $\quad$ gyroscope $96 \%$ - accelerometer $4 \%$.

Hasil pengujian yang telah dilakukan pada skenario 2 ini dibuat dalam bentuk grafik sebagai berikut

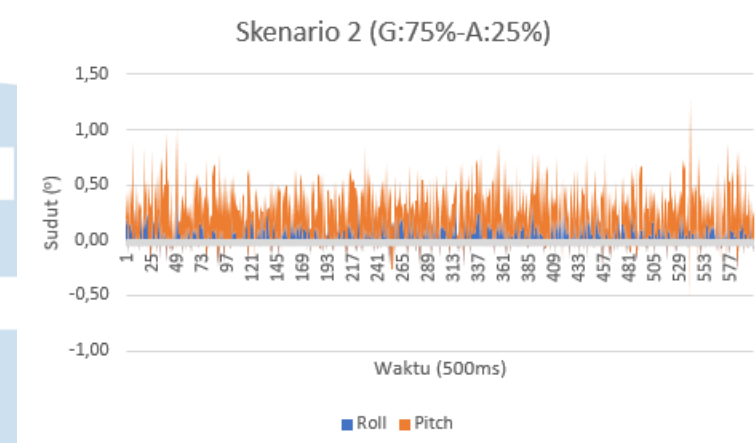

Gambar 6. Hasil pengujian Skenario 2 : gyroscope $75 \%$ - accelerometer $25 \%$

Gambar 6 memperlihatkan bahwa hasil fusion dengan penambahan accelerometer dapat membantu mengkoreksi fenomena drifting yang terjadi pada gyroscope, dan dari hasil analisis mean squared error (MSE) untuk melihat performa sensor fusion pada skenario ini didapat nilai MSE untuk posisi roll sebesar $0,01^{\circ}$ dan posisi pitch sebesar $0,14^{\circ}$. Kemudian dari hasil pengujian selanjutnya dari skenario 2 didapatkan grafik sebagai berikut

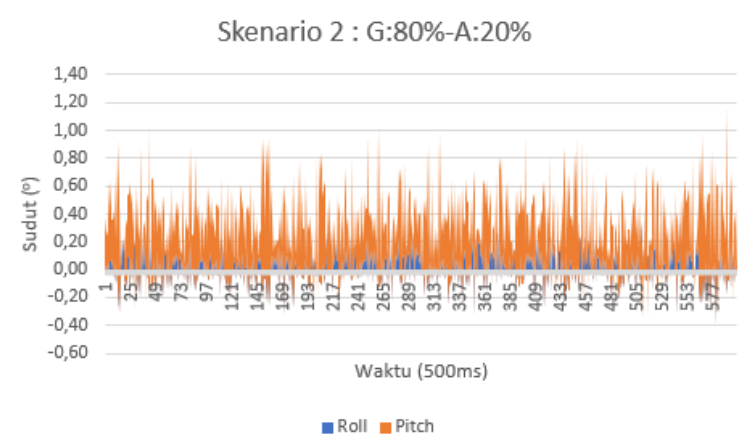

Gambar 7. Hasil pengujian Skenario 2 : gyroscope $80 \%$ - accelerometer $20 \%$

Dari hasil pengujian yang ditunjukkan oleh Gambar 7, diperoleh analisis MSE untuk posisi roll sebesar $0,01^{\circ}$ dan posisi pitch sebesar $0,21^{\circ}$. Sedangkan untuk 
pengujian skenario 2 dengan set ketiga didapat hasil sebagai berikut

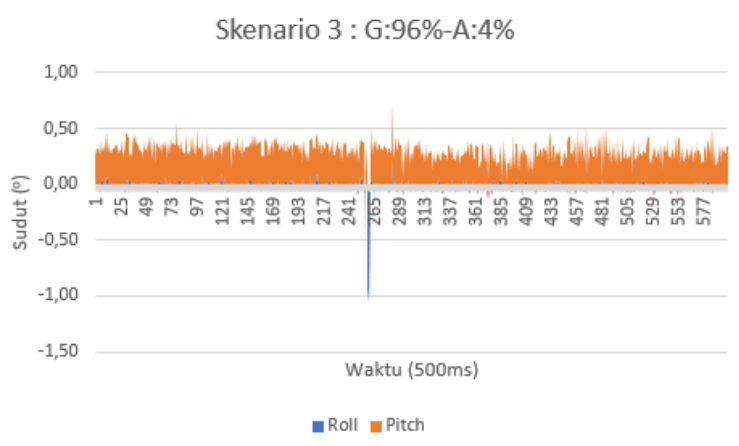

Gambar 8. Hasil pengujian Skenario 2 : gyroscope $96 \%$ - accelerometer $4 \%$

Dari hasil pengujian yang ditunjukkan oleh Gambar 8, diperoleh analisis MSE untuk posisi roll sebesar $0,00^{\circ}$ dan posisi pitch sebesar $0,11^{\circ}$.

\section{Akuisisi Data Posisi Sudut dengan Menggunakan Kalibrasi Awal Sistem Pembacaan Gyroscope.}

Pada skenario 3 ini akan dilakukan koreksi factor drifting dengan melakukan kalibrasi pengukuran, yaitu dengan mengambil data pengukuran dalam jumlah ntertentu dan menghitung rata-rata kesalahannya. Karena sistem ditempatkan pada platform rata dan tidak bergerak, maka nilai keluaran seharusnya bernilai 0 , dari situ kita dapat menghitung rata-rata kesalahan. Dari hasil pengujian kalibrasi dengan n-tertentu didapat ratarata kesalahan perhitungan yang diperlihatkan oleh Tabel 1 berikut

Tabel 1 Rata-rata offset dari keluaran MPU-6050

\begin{tabular}{|c|c|c|c|c|c|c|}
\hline \multirow{2}{*}{ No } & $\mathrm{n}$ & \multicolumn{2}{|c|}{ Accelerometer } & \multicolumn{3}{|c|}{ Gyroscope } \\
\cline { 3 - 7 } & & $\mathrm{x}$ & $\mathrm{y}$ & $\mathrm{x}$ & $\mathrm{y}$ & $\mathrm{z}$ \\
\hline 1 & 100 & -0.05 & 0.29 & 0.12 & 0.10 & $\begin{array}{c}- \\
0.05\end{array}$ \\
\hline 2 & 200 & 0.00 & 0.28 & 0.12 & 0.09 & $\begin{array}{c}- \\
0.05\end{array}$ \\
\hline 3 & 500 & -0.04 & 0.30 & 0.12 & 0.10 & - \\
& & & & & & 0.05 \\
\hline
\end{tabular}

Hasil pengujian memperlihatkan bahwa dengan melakukan n $(100,200,500)$ pengambilan data untuk melakukan kalibrasi didapatkan bahwa nilai offset dari keluaran sensor relatif sama. Dengan menggunakan nilai $\mathrm{n}=500$ sebagai faktor koreksi, didapat hasil sebagai berikut

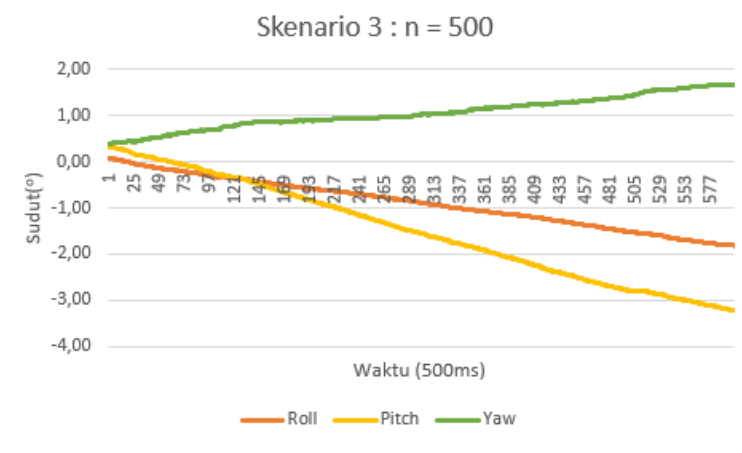

Gambar 9. Hasil pengujian Skenario 3 dengan $n=500$

Gambar 9. memperlihatkan bahwa kalibrasi awal yang dilakukan dengan menghitung nilai offset dari pembacaan sensor, dapat mengurangi fenomena drifting yang terjadi untuk pembacaan ketiga posisi sudut, baik untuk sudut roll, pitch, dan yaw. Dari hasil pengujian dapat diketahui dengan nilai pembacaan awal roll $=0,07^{\circ}$, pitch $=-0,25^{\circ}$, dan yaw $=0,06^{\circ}$, dan nilai akhir pembacaan roll $=-1,82^{\circ}$, pitch $=-1,41^{\circ}$, dan yaw $=4.88^{\circ}$ maka dapat diketahui dalam kurun waktu 300 detik laju kesalahan drifting untuk roll ialah sebesar $0,0063 \%$ detik, sedangkan untuk pitch ialah sebesar $0,0038 \%$ detik, dan yaw sebesar $0.0161 \%$ detik. Hasil tersebut memeperlihatkan secara umum proses kalibrasi yang dilakukan dapat memperbaikki performa sistem.

D. Akuisisi Data Posisi Sudut Dengan Menggunakan Kalibrasi Awal Sistem dan Konsep Sensor Fusion

Pada skenario 4, dilakukan kombinasi implementasi kalibrasi awal untuk menghilangkan nilai offset dengan nilai $n=500$ dengan konsep sensor fusion informasi antara sensor gyroscope dan accelerometer untuk penentuan posisi sudut roll dan pitch dengan tingkat kepercayaan sensor gyroscope sebesar 96\% dan accelerometer sebesar $4 \%$. Sedangkan pada penentuan posisi sudut yaw hanya digunakan metode kalibrasi awal sensor dengan nilai $\mathrm{n}=500$. Hasil dari pengujian yang dilakukan pada skenario 4 ini ditunjukkan oleh Gambar 10.

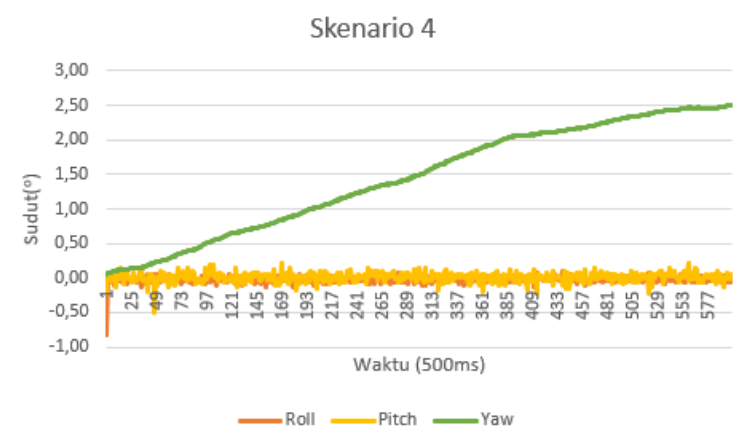

Gambar 10. Hasil pengujian Skenario 4

Dari Gambar 10 terlihat bahwa kombinasi antara kalibrasi awal dan metode sensor fusion dapat memperbaikki pembacaan posisi sudut roll, pitch, dan yaw pada sensor GY-521 MPU-6050. Analisis data 
menunjukkan dengan nilai awal pembacaan sudut roll $=-0,82^{\circ}$, pitch $=-0,22^{\circ}$, dan yaw $=0,06^{\circ}$, dan nilai akhir pembacaan roll $=0,02^{\circ}$, pitch $=0,06^{\circ}$, dan yaw $=2.51^{\circ}$, maka dapat diketahui dalam kurun waktu 300 detik hasil analisis MSE untuk posisi roll sebesar 0,0029 dan posisi pitch sebesar $0,0047^{\circ}$ dan laju kesalahan drifting pada posisi sudut yaw sebesar $0,0082^{\circ}$ detik.

\section{KESIMPULAN}

Dari hasil pengujian yang telah dilakukan, modul sensor GY-521 MPU-6050 dapat dikoneksikan dengan mikrokontroller Arduino Uno secara mudah dengan protokol komunikasi serial I2C dan memberikan informasi berupa posisi sudut. Namun pada metode pembacaan dengan nilai full scale range secara default, seperti pada sistem IMU umumnya terjadi fenomena drifting dengan laju error per detik untuk posisi sudut roll sebesar $0,084 \%$ detik, sedangkan untuk pitch sebesar $0,06 \%$ detik, dan yaw sebesar $0,022 \%$ detik. Dari implementasi metode koreksi yang dilakukan, kalibrasi awal sistem mampu memperbaikki performa pembacaan sensor dalam 300 detik dengan menurunkan laju error per detik untuk sudut roll sebesar 92,5\%, untuk posisi sudut pitch sebesar $93,67 \%$ dan untuk posisi sudut yaw sebesar $26,81 \%$. Metode sensor fusion yang dilakukan dengan mengkombinasikan informasi dari gyroscope dan accelerometer pada pembacaan posisi sudut roll dan pitch juga dapat melakukan koreksi data dan membuat pembacaan lebih stabil. Dengan beberapa metode koreksi kesalahan yang telah dilakukan pada pengujian ini didapat bahwa pada skenario 4 yaitu dengan kombinasi implementasi kalibrasi awal sistem dan penggunaan konsep fusion sensor mampu memberikan performa yang lebih baik dengan hasil analisis MSE untuk posisi roll sebesar $0,0029^{\circ}$ dan posisi pitch sebesar $0,0047^{\circ}$ dan laju kesalahan drifting pada posisi sudut yaw sebesar $0,0082 \%$ detik atau turun $62,72 \%$.

Terdapat beberapa catatan yang perlu diperhatikan dari pengujian yang dilakukan, metode koreksi ini dapat memberikan hasil yang baik dalam pembacaan sudut roll, pitch, dan yaw dengan menggunakan sensor IMU berbasis gyroscope dan accelerometer seperti modul GY-521 MPU-6050. Namun faktor uncertainty dari sensor tersebut perlu tetap diperhatikan, hal ini dapat kita lihat pada performa pengujian skenario 3 dean skenario 4. Dengan faktor koreksi offset yang sama, performa pembacaan sudut yaw dapat menjadi berbeda, walaupun cenderung lebih baik, juga dapat dilihat dari pembacaan nilai awal yang berbeda pada penempatan sensor yang sama selama pengujian. Catatan kecil pengujian ini perlu diperhatikan terutama dalam implementasi untuk sistem yang membutuhkan kepresisian tinggi dan rentang operasional yang relatif lama.

\section{DAFTAR PUSTAKA}

[1] N. Ahmad, R. A. R. Ghazilla, N. M. Khairi, and V. Kasi, "Reviews on Various Inertial Measurement Unit (IMU) Sensor Applications," Int. J. Signal Process. Syst., 2013, doi: 10.12720/ijsps.1.2.256-262.

[2] G. M. Siouris, "Missile Guidance and Control Systems," Appl. Mech. Rev., 2004, doi: 10.1115/1.1849174.

[3] C. F. Lin, Modern Navigation, Guidance, and Control Processing, no. v. 2. Prentice Hall, 1991.

[4] D. Reid, J. Ralston, M. Dunn, and C. Hargrave, "A major step forward in continuous miner automation," Jan. 2011.

[5] H. Sheng and T. Zhang, "MEMS-based low-cost strap-down AHRS research," Meas. J. Int. Meas. Confed., 2015, doi: 10.1016/j.measurement.2014.09.041.

[6] W. H. Baird, "An introduction to inertial navigation," Am. J. Phys., 2009, doi: 10.1119/1.3081061.

[7] B. Finney, "Navigation," in International Encyclopedia of the Social \& Behavioral Sciences: Second Edition, 2015.

[8] E. H. C. Harik, F. Guerin, F. Guinand, J. F. Brethe, and H. Pelvillain, "UAV-UGV cooperation for objects transportation in an industrial area," 2015, doi: 10.1109/ICIT.2015.7125156.

[9] C. Laoudias, A. Moreira, S. Kim, S. Lee, L. Wirola, and C. Fischione, "A survey of enabling technologies for network localization, tracking, and navigation," IEEE Communications Surveys and Tutorials. 2018, doi: 10.1109/COMST.2018.2855063.

[10]O. B. Kharisma, A. Wildan, Auliaullah, and F. E. Laumal, "Implementasi Sensor MPU 6050 untuk Mengukur Kesetimbangan Self Balancing Robot Menggunakan Kontrol PID," Semin. Nas. Teknol. Informasi, Komun. dan Ind., 2018.

[11]B. Siciliano and O. Khatib, Springer handbook of robotics. 2016.

[12]D. Yang, J. K. Woo, S. Lee, J. Mitchell, A. D. Challoner, and K. Najafi, "A Micro Oven-Control System for Inertial Sensors," $J$. Microelectromechanical Syst., 2017, doi: 10.1109/JMEMS.2017.2692770.

[13]H. Haiying, "Modeling inertial sensors errors using Allan variance," UCEGE reports number 20201, Master's thesis, Univ. Calgary, Sept., 2004.

[14]A. I. Mourikis and S. I. Roumeliotis, "A multi-state constraint Kalman filter for vision-aided inertial navigation," 2007, doi: 10.1109/ROBOT.2007.364024.

[15]H. Nourmohammadi and J. Keighobadi, "Fuzzy adaptive integration scheme for low-cost SINS/GPS navigation system," Mech. Syst. Signal Process., 2018, doi: 10.1016/j.ymssp.2017.06.030.

[16]F. Caron, E. Duflos, D. Pomorski, and P. Vanheeghe, "GPS/IMU data fusion using multisensor Kalman filtering: Introduction of contextual aspects," Inf. Fusion, 2006, doi: 10.1016/j.inffus.2004.07.002.

[17]B. Mccarron, "Low-Cost IMU Implementation via Sensor Fusion Algorithms in the Arduino Environment," Calif. Polytech. State Univ., 2013.

[18]D. Anggaraeni, R. Ranto, P. Estu Broto, and A. Marta, "PERFORMANSI KARAKTERISTIK SENSOR PENGUKUR KECEPATAN SUDUT BERBASIS MEMS MPU 6050 DAN ADXL 335," 2019, pp. 27-33.

[19]M. Pedley, "Tilt Sensing Using a Three-Axis Accelerometer," 2013. 